diabetics we studied and that treatment (whether by diet alone, by oral hypoglycemic agents or with insulin) restores the pattern not only of glucose and NEFA but also of HGH secretion to normal. We think these findings suggest that the abnormalities of $\mathrm{HGH}$ secretion occur secondarily to the abnormalities in insulin secretion and carbohydrate metabolism.

Further support for this idea has been derived from the study of cases of pancreatic insufficiency resulting from pancreatitis (Baird, Hunter and Kinloch, unpublished). None of these patients was known to be diabetic at the time of study, although two in fact were mildly diabetic on testing and one other had impaired carbohydrate tolerance although not of sufficient degree to be classified diabetic. All these individuals were thin and all had completely normal HGH patterns. However, one of these patients went on over the next 6 months to develop insulin-dependent diabetes and this case is interesting on several counts. In the first place he had very low IRI levels initially - less than Io $\mu \mathrm{U} / \mathrm{ml}$ throughout the period of study, with no detectable increase in response to glucose. Yet at this time the blood glucose and NEFA patterns showed only minimal abnormalities and the HGH pattern was normal. This would seem to suggest that a very small amount of circulating IRI is sufficient to maintain normal blood glucose and NEFA levels if the individual is thin and not genetically constituted diabetic. Latterly, the IRI level fell to zero and it was only then that a notable rise in HGH occurred.

\title{
REFERENCES
}

Baird, J. D. (1969). F. Endocr. 44, 139.

Beck, P., Koumans, J. H. T., Winterling, C. A., Stein, M. F., Daughaday, W. H. \& Kipnis, D. M. (1964). F. Lab. clin. Med. 64, 654 .

Grodsky, G. M. \& Benoit, F. L. (1969). In Diabetes. Proceedings of the Sixth Congress of the International Diabetes Federation, Stockholm, 1967. International Congress Series no. 172, p. 540. Amsterdam: Excerpta Medica Foundation.

Karam, J. H., Grodsky, G. M., \& Forsham, P. H. (I963). Diabetes I2, 197.

Marks, B. (1969). Br. Y. Hosp. Med. 2, r roz.

Price, W. H., Strong, J. A., Whatmore, P. B. \& McClemont, W. F. (rg66). Lancet i, 565.

Samols, E., Marri, G. \& Marks, V. (1966). Diabetes 15, 855 .

Samuels, L. T., Gilmore, R. C. \& Reinecke, R. M. (I948). F. Nutr. 36, 639.

Schultz, R. B. \& Parra, A. (r970). Diabetes r9, 492.

Unger, R. H. (1966). Diabetes 15, 500.

Yalow, R. S. \& Berson S. A. (196I). Diabetes ro, 339.

\section{The rate of carbohydrate fermentation in the rumen}

\author{
By J. D. SutTon, National Institute for Research in Dairying, \\ Shinfield, Reading RG2 $9 A T$
}

The ruminant digests food by fermentation in the reticulo-rumen (hereafter called rumen) as well as by the usual mammalian enzymes and so is able to utilize an unusually wide range of carbohydrates including, in particular, celluloses. Almost all food enters the rumen but whereas soluble sugars begin to pass further 
down the tract almost immediately, fibrous carbohydrates may remain in the rumen for many hours. The time carbohydrates spend in the rumen is of major importance in determining the site and the extent of their digestion and the factors affecting this will be considered in some detail.

\section{Time spent in the rumen}

Principles of rumen outflow. The rate of liquid outflow can be measured fairly easily. Suitable markers exist and the fluid contents are readily sampled. The concentration of non-absorbable, soluble markers declines exponentially when they are added to a rumen in a steady state (Hydén, I961). The reciprocal of the rate of decline may be defined as the turnover time and is the average time spent by the marker in the rumen. In practice a steady state does not exist and discontinuities due to the ingestion of food and water can cause incorrect interpretation of results (Warner \& Stacy, r968a).

The difficulties of labelling and sampling solid digesta have led to the use of more indirect procedures for measuring turnover times of indigestible food residues. The commonest technique has been to measure the rate of excretion in the faeces of stained foods. This can be interpreted (Blaxter, Graham \& Wainman, 1956) as showing the existence in the digestive tract of two sequential pools, which particles leave at rates proportional to their concentration. Blaxter et al. (1956) tentatively suggested that the first pool occurs in the rumen and the second in the abomasum, but Hungate ( 1966 ) considers that both pools occur in the rumen. He proposes that large food particles, when they are ingested, enter the first pool. As they are reduced in size by digestion and rumination, the particles move into the "liquid-small particle pool'. Material in the liquid-small particle pool then leaves the rumen at a rate which should be the same as that for soluble markers. If only the first pool occurs in the rumen, the amount of indigestible residues in the rumen would decline exponentially whereas if both pools occur there a sigmoidal decline, similar to the excretion of residues in the faeces, would probably be found.

Liquid outflow. Turnover times for liquid markers, obtained with sheep and cows given a variety of rations, range from about 6 to $24 \mathrm{~h}$. Probably the most important variable affecting the turnover times of liquids is the amount of food consumed. Poutiainen (1968) observed that in cows given hay and concentrates, the average turnover time of rumen liquid decreased from 22 to $8 \mathrm{~h}$ as the dry-matter intake increased from 3 to $9 \mathrm{~kg}$ daily. It was little affected by substituting concentrates for half the hay or by grinding up to $80 \%$ of the hay.

Eating and drinking cause marked increases in the rate of liquid outflow for short periods. Warner \& Stacy ( $1968 b$ ) found that, in sheep given hay once daily, the rate of outflow was equivalent to about $7 \%$ of the rumen volume per hour during the $10-\mathrm{I} 5 \mathrm{~h}$ spent resting, $\mathrm{I} 8 \%$ during eating $(\mathrm{I} \mathrm{h})$ and $10 \%$ during the $10 \mathrm{~h}$ 'postfeeding' period. Thus, food carbohydrates that dissolve quickly could leave the rumen about twice as fast as would be expected from the daily mean turnover time of liquids. 
Outflow of solids. Turnover times of indigestible hay residues usually range between $\mathrm{I}$ and $3 \mathrm{~d}$, about three times longer than average values for liquids. Outflow of solids probably varies during the day and Balch (1958) concluded that outflow of solid digesta was fastest during eating, when liquid flow is also highest.

The lack of understanding of the movement of particles through the rumen frustrates attempts to estimate turnover times more accurately. For instance, when sheep were given $1500 \mathrm{~g}$ finely ground dried grass daily by Blaxter et al. (1956) particles would have stayed in the rumen for either 2 or $24 \mathrm{~h}$ according to whether one or both pools occur in the rumen. An examination (E. W. Evans and G. R. Pearce, unpublished), with cows given $3^{-6} \mathrm{~kg}$ hay once daily, of the particle size distribution in the rumen at various times after feeding appears to support the suggestion that both pools exist in the rumen. Tentative calculations of turnover times gives values of about $\mathrm{i} 8 \mathrm{~h}$ for the large particles and $46 \mathrm{~h}$ for the small particles, which is in reasonable agreement with the times of $22 \mathrm{~h}$ and $29 \mathrm{~h}$ for the two pools that can be calculated from the data of Blaxter et al. (1956) for sheep given comparable amounts of long, dried grass.

An increase in the amount of food ingested usually decreases the turnover time of solids as well as liquids in the rumen. On the assumption that two pools of solid particles occur in the rumen, the turnover time of stained residues fell from 65 to $43 \mathrm{~h}$ as the amount of dried grass given in the long form to sheep was increased from 600 to $1500 \mathrm{~g}$ daily in the experiments of Blaxter et al. (1956). The effect of grinding hay varies. Finely ground hay included in a ration of long hay passes through the tract more rapidly than the long hay (Balch, $195^{\circ}$ ). When all the hay is ground, both increases and decreases in the rate of passage have been observed. This inconsistent response is probably related to variations in the degree of fineness of the ground hay and in the amount of food consumed. Specific gravity (Campling \& Freer, 1962) and shape (Troelsen \& Campbell, 1968), as well as size, affect the passage of particles through the tract.

Little is known about the turnover times of concentrates, but when they are included in mixed rations their residues pass more rapidly than hay residues (Balch, 1950).

\section{Rate of digestion}

Roughages. For a wide range of herbages, most digestion is complete within I2-I $8 \mathrm{~h}$ of feeding although fermentation continues at a decreasing rate for several days. The soluble carbohydrates are readily fermented and almost all disappear from the rumen within $5^{-6} \mathrm{~h}$ of the start of feeding (Hungate, Ig66; Bailey, 1967 ). They probably dissolve in the free rumen fluid during and shortly after feeding but because of the high rate at which they are fermented, their concentration remains low even with food such as sugar-beet pulp (Clapperton \& Czerkawski, 1969). The fermentation of fibrous components proceeds more slowly. Many in vitro experiments show a 'lag phase' for the first few hours followed by a steady fermentation for about $\mathrm{I} 2 \mathrm{~h}$ but it is not clear to what extent this 'lag phase' occurs in vivo. 
The rate of disappearance (digestion plus outflow) from the rumen of all the major carbohydrate fractions of roughages has been examined on very few occasions. On the basis of in vitro measurements of the rate of fermentation of various fractions of lucerne hay, Hungate ( 1968 ) calculated the theoretical disappearance rates of the various fractions from the rumen (Fig. Ia).

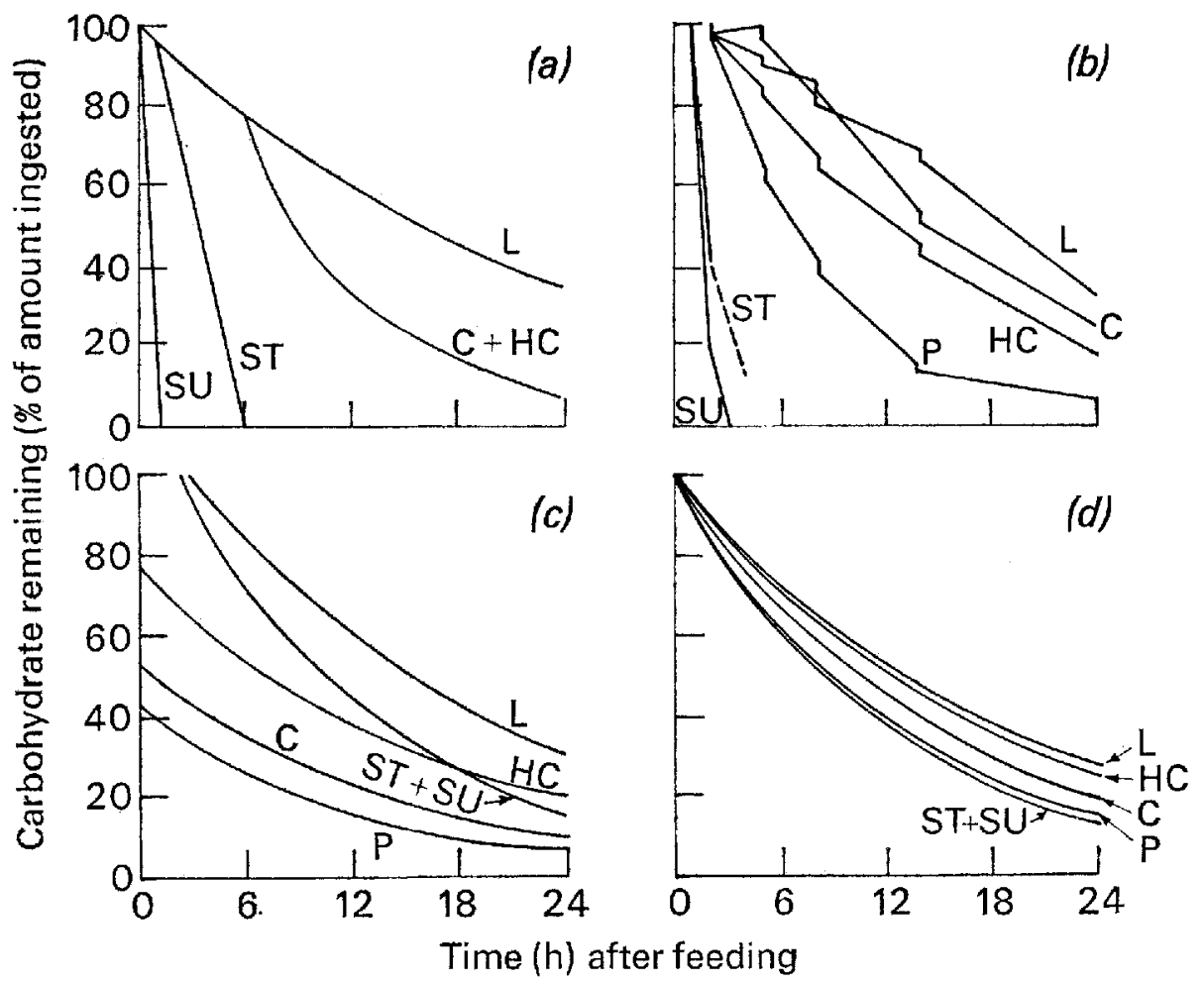

Fig. I. The disappearance from the rumen of carbohydrate fractions of legume hays $(a)$ lucerne (theoretical, Hungate, r968); (b) $6.9 \mathrm{~kg}$ clover to cows (Expt A5, Bailey, I967); (c) and (d) $5.4 \mathrm{~kg}$ pre-bud lucerne to cow (Alexander et al. 1969). $\mathrm{L}=$ lignin; $\mathrm{C}=$ cellulose; $\mathrm{HC}=$ hemicellulose; $\mathrm{P}=$ pectin; $\mathrm{ST}=$ soluble polysaccharide; $\mathrm{SU}=$ soluble sugars. For further details see text, p. 39-40.

Assuming a $24 \mathrm{~h}$ turnover time, he estimated that $2 \%$ of soluble sugar, $14 \%$ of a fraction roughly equivalent to soluble polysaccharides and $45 \%$ of the digestible fibre would escape fermentation by passage out of the rumen. Weston \& Hogan (I968) have indeed found some $10 \%$ of the soluble sugars and polysaccharides ingested reach the abomasum of sheep given various dried grasses eight times daily. Since turnover times of the liquid pool shortly after feeding are two or three times shorter than the $24 \mathrm{~h}$ assumed by Hungate, even greater quantities might conceivably reach the abomasum in sheep fed once or twice daily. The amount of fibre digestion in the rumen is underestimated by Hungate's approach. Usually only some $10-20 \%$ of the digestible cellulose escapes fermentation in the rumen.

Only two in vivo experiments have been conducted in sufficient detail to allow 
comparison with the estimates of Hungate (1968). Bailey ( 1967 ) removed, sampled and returned the total rumen contents of cows at frequent intervals for $24 \mathrm{~h}$. The cows were given fresh clover or clover hay once daily (Fig. Ib). Alexander, Meyer \& Bartley ( 1969 ) included lucerne hay, labelled with radioactive carbon, in the ration of lucerne hay given to a cow four times daily. They determined the radioactivity in various carbohydrate fractions of the rumen contents at frequent intervals for $48 \mathrm{~h}$ after giving the labelled hay. The results closely fitted an exponential decline but in many instances, especially for cellulose and pectin, the resulting equations indicated that up to $60 \%$ of the carbohydrate disappeared from the rumen at the time of ingestion (Fig.rc). This may have been due to the difficulty of identifying the carbohydrate fractions of partially digested residues in the rumen with the same fractions in the food, a problem also in Bailey's technique, and to the transfer of the radioactive label. It may be thought more reasonable to assume zero disappearance at the start of feeding in which event the results shown in Fig. Id are obtained.

The results in Fig. $1 \mathrm{a}, \mathrm{b}$ and $\mathrm{d}$ for the fibrous fractions are broadly similar and give turnover times of about $20-30 \mathrm{~h}$ for the indigestible residues (lignin). The disappearance of the more readily fermentable fractions differs seriously, that obtained by Bailey agreeing more closely with the theoretical values of Hungate. Some of the differences can be attributed to the different conditions of the experiments but the procedures of Alexander et al. (1969) appear to involve particular technical problems.

Concentrates. Despite the importance of concentrates for ruminants, the rate of their digestion in the rumen has been the subject of few critical studies. When large amounts of soluble sugars are given, for instance $3 \mathrm{~kg}$ sucrose or glucose daily as a supplement for dairy cows, only low concentrations are found in solution in the rumen and most appears to be digested within $3 \mathrm{~h}$ (J. D. Sutton, unpublished). It seems unlikely that much escapes fermentation.

Cereal starch is also rapidly digested, especially if it is cooked, and only about 5-10\% usually escapes fermentation. However, the starch of cracked maize is sometimes less completely fermented, probably because of the physical structure of the grain (Ørskov, Fraser \& Kay, 1969). The type of microbial population can also affect the rate of starch fermentation. Protozoa, unlike bacteria, are able to ingest food starch for subsequent fermentation. Recent results by Whitelaw, HyldegaardJensen, Reid \& Kay ( $197^{\circ}$ ) suggest that a large population of protozoa in the rumen can thereby reduce the rate of starch fermentation.

\section{Products of fermentation}

In the steady state the concentration of volatile fatty acids (VFA) in the rumen is roughly proportional to the rate at which they are produced. This relationship does not apply to short-term changes. The rate of production is maximal within $\mathrm{I}-2 \mathrm{~h}$ of the ingestion of a wide range of rations whereas the maximum concentration does not occur until $2-3 \mathrm{~h}$ later. The rate of VFA absorption broadly reflects the concentration of VFA in the rumen, but increases in absorption rates after feeding are probably considerably greater than increases in concentration because blood flow 
rates also rise. The rate of VFA absorption has been estimated to be five to eight times greater after feeding than before (Bensadoun, Paladines \& Reid, 1962; Whitelaw et al. 1970 ) and the animal may have difficulty in utilizing such a widely fluctuating supply of metabolites. The greater efficiency of energy utilization sometimes associated with increased feeding frequency may well be due to a reduced fluctuation in energy supply to the tissues.

When readily fermentable carbohydrates are given, products in addition to VFA are found, particularly in the early stages of fermentation. When large amounts of sugars are included in the ration, the concentration of lactic acid may reach $50-60 \mathrm{~m}$-moles/ 1 within $\mathrm{I} \mathrm{h}$ of the start of feeding and return almost to zero $2 \mathrm{~h}$ later. Appreciable amounts of microbial storage polysaccharide are also synthesized from soluble sugars. With high-concentrate rations based on flaked maize, concentrations of lactic acid in excess of $20 \mathrm{~m}$-moles/1 may last for several hours. Although a considerable proportion of the carbohydrate must be converted to lactic acid and storage polysaccharide with such rations, little is known about the subsequent fate of these products. Some is later converted to VFA but a proportion undoubtedly passes further down the tract and some of the lactic acid is absorbed from the rumen.

\section{Efficiency of carbohydrate utilization}

The fermentation of carbohydrates and the metabolism, by the host animal, of the VFA produced are inefficient methods of utilizing the energy of foods. Soluble carbohydrates and at least some starch can be digested in the small intestine so a reduction in the amount of fermentation in the rumen should improve the efficiency of energy utilization providing any starch or digestible fibre leaving the ileum is fermented in the caecum. Such a response was achieved by Thomson, Beever, Coehlo da Silva \& Armstrong (1969) when they gave sheep dried lucerne in a finely ground pelleted form. Not only did they alter the sites of digestion but they also improved the efficiency of utilization of the digestible energy (Thomson, Armstrong \& Prescott, I969). It seems likely that this response was caused by a decrease in the turnover time of the lucerne in the rumen due to grinding. However, the responses were smaller when ground dried grass replaced the lucerne and were further reduced when the amount of dried grass ingested was increased. More needs to be known about the relationship between the size of particles, their turnover time in the rumen and the extent of their digestion. Other possible methods of reducing the amount of rumen fermentation are the use of the oesophageal groove reflex, especially for soluble carbohydrates, or some form of protection as is being used successfully for proteins.

A further possible cause of inefficient use of carbohydrates in ruminants fed once or twice daily is the widely fluctuating uptake of metabolites from the gut. This fluctuation is particularly large with high-concentrate rations where efficiency may also be reduced due to the production of lactic acid. Increased feeding frequency should reduce both these problems but the variable responses to alterations in frequency of feeding show the need for further studies.

I am grateful to Dr E. W. Evans for helpful discussions. 


\section{REFERENCES}

Alexander, C. L., Meyer, R. M. \& Bartley, E. E. (1969). F. Anim. Sci. 29, 746.

Bailey, R. W. (1967). N.Z. Fl agric. Res. Io, 15.

Balch, C. C. (1950). Br. F. Nutr. 4, 36r.

Balch, C. C. (1958). Br. F. Nutr. 12, 330.

Bensadoun, A., Paladines, O. L. \& Reid, J. T. (1962). F. Dairy Sci. Io, I 203.

Blaxter, K. L., Graham, N. McC. \& Wainman, F. W. (1956). Br. f. Nutr. ro, 69.

Campling, R. C. \& Freer, M. (1962). Br. f. Nutr. 16, 507.

Clapperton, J. I. \& Czerkawski, J. W. (1969). Br. F. Nutr. 23, 81 3.

Hungate, R. E. (1966). The Rumen and Its Microbes. New York: Academic Press.

Hungate, R. E. (I968). In Handbook of Physiology, Section 6, Vol. 5, p. 2725 [C. F. Code, editor]. Washington, D.C.: American Physiological Society.

Hydén, S. (1961). LantbrHögsk. Annlr 27, 51.

Orskov, E. R., Fraser, C. \& Kay, R. N. B. (1969). Br. F. Nutr. 23, 217.

Poutiainen, E. (1968). Annls Agric. fenn. 7, Suppl. 3 .

Thomson, D. J., Armstrong, D. G. \& Prescott, J. H. D. (1969). Proc. Eur. Grassld Fedn, Third Meeting, Braunschweig, p. 253 .

Thomson, D. J., Beever, D. E., Coehlo da Silva, J. F. \& Armstrong, D. G. (1969). Proc. Nutr, Soc. $28,24 \mathrm{~A}$.

Troelsen, J. E. \& Campbell, J. B. (1968). Anim. Prod. ro, 289.

Warner, A. C. 1. \& Stacy, B. D. (I968a). Br. F. Nutr. 22, 369.

Warner, A. C. I. \& Stacy, B. D. (I $968 b$ ). Br. J. Nutr. 22, 389.

Weston, R. H. \& Hogan, J. P. (1968). Aust. Y. agric. Res. 19, 963.

Whitelaw, F. G., Hyldegaard-Jensen, J., Reid, R. S. \& Kay, M. G. (1970). Br. F. Nutr. 24 , I79.

\section{Response of the liver to protein feeding}

By A. Fleck, W. H. Wunner, A. R. Henderson, Fiona C. Ballantyne and W. J. Tilstone, Royal Infirmary, Glasgow

In a review entitled 'Regulation of protein metabolism', Munro (I964) summarized the work up to 1963 on the response of the liver to dietary protein and emphasized the extent of the changes which take place. The early work of Addis, Poo \& Lew (1936) and the subsequent work of Kosterlitz (1947) was definitive. In the rat, $4 \mathrm{~d}$ of feeding a protein-free diet leads to a reduction in liver protein of about $25 \%$ (Addis et al. 1936), and corresponding changes in phospholipids and nucleic acids (Kosterlitz, 1947). Numerous studies of the effects of protein deprivation and refeeding have been carried out (see Munro, i 964). Lagerstedt (1949), for example, illustrated the disappearance of RNA from both cytoplasm and nucleolus during starvation and its reappearance on feeding a high-protein diet. The cellular control mechanisms involved in these changes is discussed in an extensive review by Munro ( $197^{\circ}$ ). The aim of the present paper is to review and collect together our own work on the response of the liver to protein feeding.

It has been recognized for some years that changes occur in the endoplasmic reticulum, or microsome fraction of homogenized tissue, when the protein content of the diet is altered (Bernhard \& Rouiller, 1956). This earlier work described the changes following starvation; however, Wunner $(1967 b)$ confirmed that similar changes occurred in animals given amino acid deficient mixtures. Protein deprivation 